\title{
Effects of intravenous immunoglobulin therapy on patients of guillain barré syndrome in intensive care unit of BSMMU - a retrospective study
}

\author{
Debasish Banik $^{1}$, Qumrul Huda ${ }^{1^{*}}$, Labib Imran Faruque ${ }^{2}$, Md. Abdul Hye ${ }^{1}$ \\ ${ }^{1}$ Department of Anaesthesia, Analgesia \& Intensive Care Medicine, Bangbandhu Sheikh Mujib Medical University, Shahbag, \\ Dhaka, ${ }^{1}$ Research fellow, ICDDR,B Dhaka. \\ * Corresponding author: Email- qhuda309@Gmail.com.
}

\begin{abstract}
:
Acute polyneuropathy or Guillain Barré syndrome (GBS) following respiratory, gastrointestinal and other illness cause a world wide morbidity and mortality. Immunotherapy (IgG) is early phase of GBS is supposed to reduce life threatening complications. In our retrospective study in ICU, BSMMU Dhaka from January 2007 to December 2008, we included 43 patients admitted during that time. Among the patients 15 patients who received IgG therapy, 1 (one) patient died and 8 patients died among 28 who did not receive Immunotherapy. Recovery rate was $91.66 \%$ among IgG group and $66.67 \%$ in non IgG group. Ventilated Patients were $53.33 \%$ in IgG group and $71.43 \%$ patients were in non IgG group. The average duration of stay was 35 days in IgG group and 39.18 days in non-IgG group. The average duration of stay was 22.57 days in IgG group who received immunotherapy in 0-4 days of onset of symptoms and 45.88 days in who got immunotherapy in 5-8 days of onset of symptoms. It is clearly evident that IgG therapy in early phase of GBS reduces, morality, morbidity and duration of hospital (ICU) stay and IgG therapy in early phase of GBS is a better treatment option.
\end{abstract}

Key Words: GBS, immunoglobulin.

(Journal of BSA, 2008; 21(2): 72-75)

\section{Introduction:}

Guillain Barré syndrome (GBS) is an autoimmune disorder encompassing a heterogeneous group of pathological and clinical states ${ }^{1}$. Antecedent infection (1-3 weeks or longer) vaccination, neural injury are thought to trigger autoimmune response which subsequently cross reacts with nerve leading the demyelination or axonal degeneration. An about 60 percent of cases the major clinical manifestation is paresis and paraplegia of lower limbs which is ascending and often needs intensive care unit support for respiration ${ }^{2}$. The essential points in the therapy of acute severe cases are respiratory assistance and careful nursing, since the disease remits naturally and recovery is complete in majority of cases. But many of the patients become disable or even may die due to fatal complications. The Dutch study group has reported that intravenous immunoglobulin $(0.4 \mathrm{~g} / \mathrm{kg} /$ day for 5 consecutive days) is effective as plasma exchange therapy and has the advantage of immediate availability and greater safety ${ }^{3}$. The Aim of this study was whether early immunotherapy ( $1^{\text {st }}$ week) reduces hospital (ICU) stay, morbidity and mortality.

\section{Methods:}

We have conducted a retrospective study from the patients admitted in the ICU of BSMMU and Millennium Heart and General hospital with the diagnosis of Guillain Barré syndrome. We have identified 43 patients from January 2007 to December 2008. We reviewed the medical records, admission registrar and individual patient files. We have used a structured questionnaire to get the demographic, clinical, laboratory diagnostic, management and therapeutic information.

We used MS access for data entry. We have analyzed data in using the data analysis software SPSS. We have determined P-value as 0.05 as statistically significant. 


\section{Results and interpretation:}

Among 43 Guillain Barré syndrome patients, 25 percent patients were of age ranges between 10 years to 19 years. Seventy percent was male patients.

Table I

Demographic status

\begin{tabular}{lcc}
\hline Age Age classification & No & Percent \\
\hline lowest through 9 years & 8 & 18.6 \\
10 - 19 years & 11 & 25.6 \\
20 - 29 years & 8 & 18.6 \\
30 - 39 years & 6 & 14.0 \\
40 - 49 years & 4 & 9.3 \\
more than 50 years & 6 & 14.0 \\
Sex Male & 30 & 69.8 \\
Female & 13 & 30.2 \\
\hline
\end{tabular}

Clinical parameters included prodromal symptoms and onset of motor weakness. Total 20 patients (46.5\%) had prodromal symptoms (for example fever, diarrhea) one to four weeks prior the gradual onset of muscle weakness. Typical presentation of lower limb muscular weakness had been seen in 81 percent patients. Twenty eight patients develop paralysis in respiratory muscles and eventually diagnosed as impending respiratory failure.

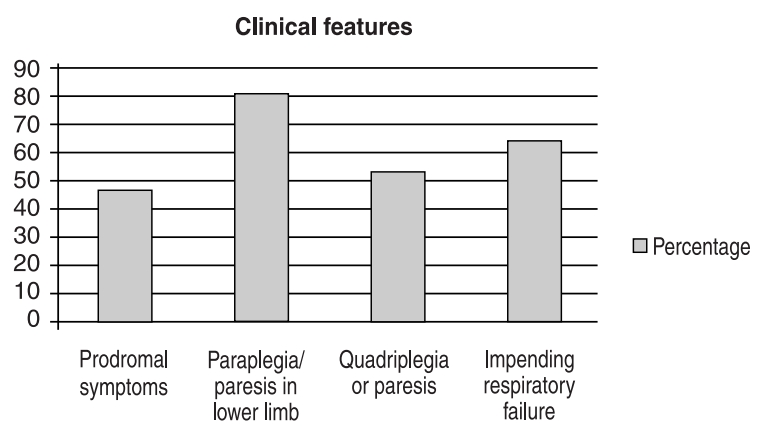

Fig.-1: Clinical characteristics

Immunoglobulin had been administered in 15 patients. All the 28 patients had been developed respiratory failure were undergone mechanical ventilation. However, fifteen patients failed to wean from mechanical ventilation and extubation, therefore tracheostomy was performed in those patients.

\section{Therapies and interventions}

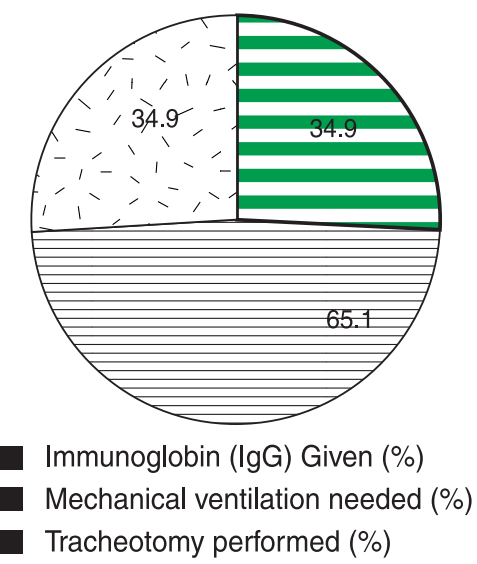

Fig.-2: Therapies and interventions

Immunoglobulin therapy administration influences length of ICU stay. Among 43 GBS patients 15 patients were given IgG. Those who have received immunoglobulin have lower hospital stay (35 days) in comparison to those who have not got immunotherapy (39.8 days).

Table - II

Clinical characteristics of the participants based on immunoglobin (IgG) therapy

\begin{tabular}{lcc}
\hline & $\begin{array}{c}\text { IgG receivedIgG not received } \\
(\mathrm{n}=15) \\
\text { in percent }\end{array}$ & $\begin{array}{c}(\mathrm{n}=28) \\
\text { in percent }\end{array}$ \\
\hline Clinical Presentations & & \\
Prodromal symptoms & 46.66 & 46.43 \\
Lower limb paralysis & 86.66 & 78.57 \\
$\begin{array}{l}\text { Quadriplegia } \\
\text { Respiratory failure }\end{array}$ & 53.33 & 53.57 \\
Speech disturbance & 60 & 67.86 \\
Cranial neuropathy & 13.33 & 17.86 \\
Sensory deficit & 2.1 & 28.6 \\
Relevantinvestigations & 20 & 3.6 \\
Nerve conduction test & 6.67 & 3.57 \\
Performed & & \\
Cerebrospinal fluid study & 20 & 32.14 \\
Performed & & \\
Performed procedures & & \\
Ventilation & 53.33 & 71.43 \\
Trachestomy & 20 & 42.86 \\
Outcomes & & \\
Complications & 6.66 & 28.57 \\
Co-morbidities & 13.33 & 28.57 \\
Recovery* & 91.66 & 66.67 \\
\hline
\end{tabular}

* Prognostic value assessed. 
Table - III

Intervening procedures and care pattern of the participants based on immunoglobulin (IgG) therapy.

\begin{tabular}{lccc}
\hline & $\begin{array}{c}\text { IgG given }(\mathrm{n}=15) \text { in } \\
\text { mean value } \pm \text { SD }\end{array}$ & $\begin{array}{c}\text { IgG not given }(\mathrm{n}=28) \\
\text { in mean value } \pm \mathrm{SD}\end{array}$ & P-value \\
\hline Age in years & $26.27 \pm 21.55$ & $28.07 \pm 19.52$ & 0.78 \\
Days of hospitalization* & $35 \pm 37.83$ & $39.18 \pm 33.59$ & 0.71 \\
Admission delay after onset of illness in days & $7.13 \pm 8.95$ & $8.52 \pm 7.42$ & 0.61 \\
\hline
\end{tabular}

*Prognostic value assessed.

Table - IV

Intervening procedures and care pattern of the participants in two groups of immunoglobulin (IgG) therapy

\begin{tabular}{lccc}
\hline & $\begin{array}{c}\text { IgG in 0-4 days in } \\
\text { mean value } \pm \text { SD }\end{array}$ & $\begin{array}{c}\text { IgG in 5-8 days in } \\
\text { mean value } \pm \text { SD }\end{array}$ & $\begin{array}{c}\text { P- } \\
\text { value }\end{array}$ \\
\hline Age of patients & $22.29 \pm 20.81$ & $29.75 \pm 22.96$ & 0.52 \\
Days of hospitalization* & $22.57 \pm 18.46$ & $45.88 \pm 47.75$ & 0.23 \\
Interval between ventilation and IgG therapy in days & $0.8 \pm 1.57$ & $1.25 \pm 3.9$ & 0.62 \\
Admission delay after onset of illness in days* & $2.71 \pm 1.98$ & $11.00 \pm 10.98$ & 0.07 \\
\hline
\end{tabular}

*Prognostic value assessed.

Immunoglobulin had been administered in 15 patients and 91 percent recovered. Twenty patients recovered and eight patients had died among 28 patients who had not received immunoglobulin. Endotracheal intubation and mechanical ventilation had been performed in 28 pateints. Eight patients had been ventilated among 15 patients who received immunoglobulin. Seventy one percent patients were mechanically ventilated but did not receive any IgG therapy.

Among 15 patients who received immunoglobulin, mean duration of immunoglobulin initiation after hospitalization was 4.2 days; therefore those who received immunoglobulin were divided into 0-4 days and 5-8 days. Immunoglobulin therapy administration influences length of ICU stay. Among 43 GBS patients 15 patients were given IgG. Those who have received immunoglobulin earlier have lower hospital stay (22.57 days) in comparison to those who have not got immunotherapy (45.88 days).

\section{Discussion:}

Immunotherapy in early phase of Guillain Barré syndrome hasten recovery, reduces mortality and morbidity. The Dutch study group has reported that intravenous (I/V) administration of immunoglobulin ( $0.4 \mathrm{~g} / 14$ for 5 consecutive days) is effective as plasma exchange (PE) and has the advantages of immediate availability and greater safety ${ }^{3}$. In our study 15 patients received immunotherapy out of 43 patients and only patient died and 28 patients did not get immunotherapy 8 patients died which signifies more number of deaths in those who did not received immunoglobulin. Recovery rate was $91.66 \%$ among IgG group $66.47 \%$ in non IgG group. In IgG group $53.33 \%$ patients were ventilated and $71.43 \%$ were in non-IgG group. The average duration of stay is 35 days in IgG group and 39.18 days in non-IgG. The average duration of stay 22.57 days in IgG group who received immunotherapy in 0-4 days of onset symptom and 45.88 days in who got immunotherapy in 5-8 days of onset of symptom. Hughes et.al reported I/V IgG hasten recovery in non-ambulant GBS with in 14-28 days of symptoms ${ }^{4}$. In the Dutch trial pneumonia, atelectasis, haemodynamic disturbance occurred more after with plasma exchange therapy than I/V IgG therapy ${ }^{3}$. But we did not go for plasma exchange (PE) therapy. Gürses et al. reported with IgG therapy seven of nine children recovered completely ${ }^{5,6,7}$. Combination treatment with I/V IgG and PE does not have 
superior effect than treatment regime given alone ${ }^{4}$. Similarly a combined evidence from trials show no benefit from corticosteroid therapy and the results of a trials of the methylprednesolne is still awaiting.

So it is evident that I/V IgG therapy alone in early phase of GBS is a better option for treatment. Although the results of our study were not statistically significant (may be due to small sample size), but it is clinically proved that immunotherapy in early phase of GBS reduces mortality, morbidity, duration of hospital (ICU) stay in terms of percentage and mean. Immunotherapy is effective in GBS patients in Bangladesh as shown in other studies in different countries ${ }^{3-7}$.

\section{References:}

1. Udaya Seneviratne; Guillain Barré Syndrome Postgraduate Medical Journal 2000; 76: 774782

2. Adams R P. Diseases of the spinal cord and peripheral nerves; Principles of Neurology $6^{\text {th }}$ edition. New York; McGraw Hill 1997: 13121318.

3. Van der Meché FGA, Schmitz PIM, Dutch Guillain Barré Study Group. A randomized trial comparing intravenous immune globulin and plasma exchange in Guillain Barré syndrome. N Engl J Med 1992; 326: 1123-1129.

4. R.A.C Hughes et al. Immunotherapy for Guillain Barré syndrome; Journal of American Academy of Neurology 2003; 61: 736 - 740.

5. Gürses N, Uysal S, Cetinkaya F, et al. intravenous immunoglobulin treatment in children with Guillain Barré syndrome . Scand J Infect Dis 1995; 27: 241-243.

6. Abd-Allah SA, Jansen PW, Ashwal S, Perkin RM. Intravenous immunoglobulin as therapy for pediatric Guillain Barré syndrome. J Child neurol 1997; 12:376-380.

7. Shahar E, Murphy EG, Roifman CM. Benefit of intravenously administered immune serum globulin in patients with Guillain Barré syndrome. J Pediatric1990; 116:141-144.

8. The Dutch Guillain Barré Study Group. Treatment of Guillain Barré syndrome with high-dose immune globulins combined with methylprednisolone: a pilot study. Ann Neurol 1994; 35: 749-752. 